\title{
Controlled Formation of Iron Carbides and their Performance in Fischer-Tropsch Synthesis
}

Tim A. Wezendonk ${ }^{[a, b]}$, Xiaohui Sun ${ }^{[a]}$, A. Iulian Dugulan ${ }^{[c]}$, Arno J.F. van Hoof ${ }^{[d]}$, Emiel J.M. Hensen ${ }^{[d]}$, Freek Kapteijn ${ }^{[a]}$ and Jorge Gascon ${ }^{*[a, b]}$

\begin{abstract}
Iron carbides are unmistakably associated with the active phase for Fischer-Tropsch synthesis (FTS). The formation of these carbides is highly dependent on the catalyst formulation, the activation method and the operational conditions. Because of this highly dynamic behavior, studies on active phase performance often lack the direct correlation between catalyst performance and iron carbide phase. For the above reasons, an extensive in situ Mössbauer spectroscopy study on highly dispersed Fe on carbon catalysts (Fe@C) produced through pyrolysis of a Metal Organic Framework was coupled to their FTS performance testing. The preparation of Fe@C catalysts via this MOF mediated synthesis allows control over the active phase formation and therefore provides an ideal model system to study the performance of different iron carbides. Reduction of fresh Fe@C followed by low-temperature Fischer-Tropsch (LTFT) conditions resulted in the formation of the $\varepsilon^{\prime}-\mathrm{Fe}_{2.2} \mathrm{C}$, whereas carburization of the fresh catalysts under high-temperature Fischer-Tropsch (HTFT) resulted in the formation of $\chi-\mathrm{Fe}_{5} \mathrm{C}_{2}$. Furthermore, the different activation methods did not alter other important catalyst properties, as pre- and post-reaction transmission electron microscopy (TEM) characterization confirmed that the iron nanoparticle dispersion was preserved. The weight normalized activities (FTY) of $\chi-\mathrm{Fe}_{5} \mathrm{C}_{2}$ and $\varepsilon^{\prime}-\mathrm{Fe}_{2.2} \mathrm{C}$ are virtually identical, whilst it is found that $\varepsilon^{\prime}-$ $\mathrm{Fe}_{2.2} \mathrm{C}$ is a better hydrogenation catalyst than $\chi$ - $\mathrm{Fe}_{5} \mathrm{C}_{2}$. The absence of differences under subsequent HTFT experiments, where $\chi-\mathrm{Fe}_{5} \mathrm{C}_{2}$ is the dominating phase, is a strong indication that the iron carbide phase is responsible for the differences in selectivity.
\end{abstract}

\section{Keywords}

Fischer Tropsch Synthesis, Fe Catalysis, Metal Organic Framework, MOF mediated synthesis 


\section{Introduction}

In the early years surrounding the discovery of the atmospheric-pressure synthesis, Fischer postulated that the primary step before hydrogen addition is the carbon monoxide dissociation, and thus, the formation of carbides as intermediate compounds in the reaction [1, 2]. Cobalt, nickel and iron, three metals that display FTS activity, react at $200{ }^{\circ} \mathrm{C}$ with carbon monoxide to form carbides, and carbon balances of synthesis reactions and product analysis of the decomposition of spent catalysts indicated that carbides were formed during the synthesis [3]. At this time, catalyst characterization techniques were still emerging, as only fifteen years had passed since the Nobel Prize in Physics was awarded to the Braggs for their work on X-ray diffraction (XRD), and it would be another five before Brunauer and Emmett started publishing on Van der Waals adsorption isotherms. The first iron-phase characterization studies were performed on the high-temperature FischerTropsch (HTFT) catalyst, fused bulk iron catalysts with low surface area, where the iron phase was resolved by magnetization experiments [4]. The temperature-dependent magnetic moments allowed for quantification of the iron phase during FTS, and showed that, after complete reduction, iron was converted in magnetite and Hägg carbide (around $45 \%$ and $50 \%$, resp.) with small amounts of metallic iron remaining. The composition of the catalyst changed, as the magnetite phase gradually increased during operation, whereas the Hägg carbide phase decreased and was oxidized and interconverted to another iron carbide phase [5]. This fundamental view on the dynamics of iron catalysts has not changed much up to date.

The discovery of Mössbauer absorption spectroscopy and the further development of XRD allowed the characterization of small iron nanoparticles on supported catalysts, and several iron carbides were identified over the years [6-18]. In addition, the application of X-ray photoelectron spectroscopy (XPS) and X-ray absorption spectroscopy (XANES/EXAFS) further stimulated the studies into FTS carbide-phase formation. The carbide phases found in literature associated with FTS are $\varepsilon-\mathrm{Fe}_{2} \mathrm{C}, \varepsilon^{\prime}-$ $\mathrm{Fe}_{2.2} \mathrm{C}, \mathrm{Fe}_{7} \mathrm{C}_{3}, \chi-\mathrm{Fe}_{5} \mathrm{C}_{2}$, and $\theta-\mathrm{Fe}_{3} \mathrm{C}$, however, generally, the monoclinic Hägg carbide $\left(\chi-\mathrm{Fe}_{5} \mathrm{C}_{2}\right)$ and hexagonal closed packed carbide $\left(\varepsilon^{\prime}-\mathrm{Fe}_{2.2} \mathrm{C}\right)$ are the predominant carbide phases found. Debate emerged regarding activity and selectivity of the different iron carbides, now that it became more widely accepted that carbides are the active phase. Thus, many studies have focused on the activation of fresh catalysts in order to optimize their performance and establish the iron phases [1942]. Particularly, Mössbauer studies coupled with catalytic tests provide good insight into the effect of the activation protocol and operational regime on the carbide phase. However, the focus of these papers was often limited; either the differences in the evolution of the active phase were investigated or the performance of the catalysts acquired through different activation protocols was reported. Hence, the main conclusion usually derived is that one activation method is preferred over the other, for a wide variety of reasons, and that a coexistence of carbide phases could be obtained. Therefore, it is not possible to uniquely determine key performance indicators such as activity and selectivity 
inherent to a specific iron carbide phase. To properly quantify their intrinsic activity and distinguish the iron carbides, one would need to find a very robust catalyst that can withstand the different activation regimes to maintain identical reducibility, degree of carburization, and catalytic stability.

The discovery and development of a new type of iron catalyst produced through the decomposition of highly porous, crystalline, and dispersed iron clusters in carbon matrices, or metal-organic frameworks (MOFs) was recently reported by our group [43-45]. The Fe@C catalysts have a high loading of monodispersed nanoparticles and show high degree of carburization during in situ Mössbauer experiments following the MOF pyrolysis (Table 1). Moreover, the resulting Fe@C catalysts display exceptional activity and stability under high temperature Fischer-Tropsch (HTFT, $320{ }^{\circ} \mathrm{C}, 20$ bar) conditions due to the embedding of iron in the carbon matrix formed after MOF decomposition. These catalysts provide an ideal model system because of the control over the particle size and iron phase by tuning the degree of carbonization through the pyrolysis temperature [45]. It has been observed that with increasing particle size a higher $\chi-\mathrm{Fe}_{5} \mathrm{C}_{2}$ over $\varepsilon^{\prime}-\mathrm{Fe}_{2.2} \mathrm{C}$ ratio is formed as determined by Mössbauer spectroscopy. Additionally, in situ Mössbauer experiments following the pyrolysis of the Fe-BTC precursor and its carburization confirmed that $\varepsilon^{\prime}-\mathrm{Fe}_{2.2} \mathrm{C}$ is indeed a stable phase under HTFT conditions for particles below $\sim 3 \mathrm{~nm}$. However, after reduction and subsequent activation under HTFT conditions, controlling and isolating the hexagonal carbide phases under HTFT is tedious. The low carbon chemical potential under HTFT does not allow the formation of single phase $\varepsilon^{\prime}-\mathrm{Fe}_{2.2} \mathrm{C}$ when starting from the fully oxidized iron nanoparticles.

In this study, the previous HTFT work and abundant literature data on iron catalyst activation are applied to produce different iron carbides in order to compare their performance at steady state operation over $100 \mathrm{~h}$. To demonstrate the intrinsic carbide performance, $\chi$ - $\mathrm{Fe}_{5} \mathrm{C}_{2}$ and $\varepsilon^{\prime}-\mathrm{Fe}_{2.2} \mathrm{C}$ phases are prepared from the same MOF-derived Fe@C catalysts using syngas activation and hydrogen reduction followed by low-temperature Fischer-Tropsch (LTFT) experiments. The catalyst phase during activation and LTFT is derived from in situ Mössbauer spectroscopy and the activation and LTFT experiments are carried out in parallel in fixed-bed reactor operation, both starting from catalysts produced by pyrolysis of the same MOF at 500 and $600{ }^{\circ} \mathrm{C}$ (hereafter Fe@C-500 and Fe@C-600, respectively). TEM analysis of the fresh and spent catalysts is performed to ensure proper structure-activity relations are obtained by maintaining nanoparticle dispersion. While this study does not aim to elucidate the active sites and intermediates present on the highly dynamic surface of the bulk carbide phases, it unequivocally demonstrates the effect of the carbide bulk phase on the activity and selectivity of the catalysts. 
Table1 Fe@C catalyst characterization* after passivation; $T_{\text {pyro }}$ denotes the pyrolysis temperature in ${ }^{\circ} \mathrm{C}$.

\begin{tabular}{lllllll}
\hline$T_{\text {pyro }} /{ }^{\circ} \mathrm{C}$ & $w_{\mathrm{Fe}} / \%$ & $d_{p} / \mathrm{nm}$ & $\gamma-\mathrm{Fe}_{2} \mathrm{O}_{3} / \%$ & $\mathrm{Fe} / C_{\text {surf }} /-$ & $S_{\mathrm{BET}} / \mathrm{m}^{2} \mathrm{~g}^{-1}$ & $V_{P} / \mathrm{cm}^{3} \mathrm{~g}^{-1}$ \\
\hline 500 & 37.8 & 3.6 & 95 & 0.021 & 281 & 0.30 \\
600 & 43.8 & 6.0 & 92 & 0.016 & 339 & 0.32 \\
\hline
\end{tabular}

*Iron loading in wt\% $\left(w_{F e}\right)$, average iron nanoparticle size $\left(d_{p}\right)$, percentage of bulk iron oxide phase $\left(g-\mathrm{Fe}_{2} \mathrm{O}_{3}\right)$, iron to carbon ratio on the surface $\left(F e / C_{\text {surf }}\right)$, BET area $\left(S_{B E T}\right)$ and total pore volume $\left(V_{P}\right)$ per gram of catalyst.

\section{Experimental}

Fe@C-500 and Fe@C-600 were synthesized by our earlier reported MOF mediated synthesis approach [43-45], where approximately $1.0 \mathrm{~g}$ of as-received Fe-BTC Basolite F300 was placed inside a crucible and subjected to pyrolysis at 500 or $600{ }^{\circ} \mathrm{C}$ for $8 \mathrm{~h}$ in a horizontally located quartz tubular reactor under a nitrogen gas hourly space velocity of $4.5 \mathrm{~h}^{-1}$. The resulting nanoparticles were passivated in $5 \%$ oxygen in nitrogen at room temperature, however, they were extremely prone to oxidation, witnessed by a conversion over $92 \%$ of the reduced iron phase into maghemite $\left(\gamma-\mathrm{Fe}_{2} \mathrm{O}_{3}\right)$. The following key experimental procedures are addressed in a concise manner to display the similarities in the characterization and testing. For full technical details, the reader is referred to the Supplementary material and references therein. The catalytic performance tests (Figure S1) [46] and in situ Mössbauer experiments (Figure S2) [45] were carried out in stainless steel tubular reactors of $4 \mathrm{~mm}$ and $15 \mathrm{~mm}$ internal diameter, respectively. The catalysts were pretreated either by atmospheric hydrogen reduction or pressurized syngas activation, denoted herein as reduction and carburization, respectively. Reduction comprises feeding pure hydrogen at an atmospheric pressure while ramping the temperature to $400{ }^{\circ} \mathrm{C}$ at a rate of $2{ }^{\circ} \mathrm{C} \mathrm{min}-1$, allowing reduction for $3 \mathrm{~h}$ at a space velocity based on catalyst weight (WHSV of approximately $90 \mathrm{dm}^{3} \mathrm{H}_{2} \mathrm{gFe}^{-1} \mathrm{~h}^{-1}$. The activated catalyst is cooled down to FTS reaction temperature of $230{ }^{\circ} \mathrm{C}$ under hydrogen flow. The pressure was subsequently increased to 20 bar, and carbon monoxide introduction followed during a period of $1 \mathrm{~h}$ to obtain a $\mathrm{H}_{2} / \mathrm{CO}$ ratio of unity with a WHSV of $55 \mathrm{dm}^{3} \mathrm{H}_{2} / \mathrm{CO} \mathrm{gFe}^{-1} \mathrm{~h}^{-1}$. Carburization comprises feeding equimolar syngas at 15 bar while ramping the temperature to $340{ }^{\circ} \mathrm{C}$ at a rate of $2{ }^{\circ} \mathrm{C} \min ^{-1}$, effectively carburizing the catalyst for a period of $140 \mathrm{~h}$ at a WHSV of $120 \mathrm{dm}^{3} \mathrm{H}_{2} / \mathrm{CO}_{\mathrm{Fe}}{ }^{-1} \mathrm{~h}^{-1}$. The activated catalyst is cooled down to FTS reaction temperature of $230{ }^{\circ} \mathrm{C}$ under syngas flow. The pressure was subsequently increased to 20 bar and the WHSV decreased to $55 \mathrm{dm}^{3} \mathrm{H}_{2} / \mathrm{CO}_{\mathrm{Fe}}{ }^{-1} \mathrm{~h}^{-1}$. The weight hourly space velocities for activation and FTS were increased by a factor 2.0 for the in situ Mössbauer cell to overcome the inherent dimensional mismatch in the internal diameter. With increased space velocities, a better approximation to plug flow behavior through the wider tubular 
reactor can be achieved, which also diminishes adverse effects otherwise caused by higher partial pressures of water and carbon dioxide due to the lower superficial gas velocity. Differential reactor operation and isothermal conditions were ensured for the two experimental techniques, aiming at conversion levels between 5-15\% under LTFT conditions. Spent catalysts from the performance tests were passivated for a period of $3 \mathrm{~h}$ in the abovementioned quartz tubular reactor by flowing $5 \%$ oxygen in nitrogen at room temperature through the packed beds inside their stainless-steel tubes. Transmission ${ }^{57} \mathrm{Fe}$ Mössbauer spectra were collected at $300 \mathrm{~K}$ and $4.2 \mathrm{~K}$ with a sinusoidal velocity spectrometer using a ${ }^{57} \mathrm{Co}(\mathrm{Rh})$ source and velocity calibration was carried out using an $\alpha-\mathrm{Fe}$ foil, the resulting Mössbauer spectra were fitted using the Mosswinn 4.0 program [47]. Debye temperatures were calculated using a Levenberg-Marquardt fitting algorithm of the Lamb-Mössbauer factor [48, 49], using the Debye model approximation. TEM imaging was carried out on passivated catalysts prepared on a well-conducting copper grid with a support of lacey carbon and an additional $2 \mathrm{~nm}$ carbon film. The images were acquired on a CryoTitan at room temperature operated at $300 \mathrm{kV}$ and equipped with a field emission gun using a Gatan $2 \mathrm{k} \times 2 \mathrm{k}$ CCD camera. The structures of the carbon matrix from the catalyst and the carbon grid of the TEM showed distinct differences.

\section{Results and Discussion}

\subsection{In situ Mössbauer Absorption Spectroscopy}

The room temperature spectra of the fresh Fe@C-500 catalyst (Figure S3, Table S1) indicate the presence of very small iron nanoparticles, as also shown by TEM and XRD. From the isomer shift of $0.31 \mathrm{~mm} \mathrm{~s}^{-1}$ and an average magnetization of zero [23], it can be derived that over $90 \%$ of $\mathrm{Fe}$ is present as superparamagnetic iron oxide nanoparticles with size smaller than $4 \mathrm{~nm}$ [45]. Under cryogenic temperatures, the contributions of the tetrahedral and octahedral sites of maghemite $(\gamma$ $\mathrm{Fe}_{2} \mathrm{O}_{3}$ ) are distinguished, next to a large contribution of unresolved iron oxides with an average hyperfine field of $48.4 \mathrm{~T}$ resulting from the presence of distribution of particles of different size. [21]. As carburization initiates under HTFT conditions, the iron oxides are gradually reduced towards carbides and nonstoichiometric oxides over time, as can be seen from the spectra taken after $24 \mathrm{~h}$ and $96 \mathrm{~h}$ (Figure S4, Table S2). The room temperature spectra are most clear in displaying the trend of carbide phase growth and change in the nature of the oxide. The oxide exhibits an isomer shift of $1.06 \mathrm{~mm} \mathrm{~s}^{-1}$, much larger than the oxide of the fresh catalyst. At cryogenic temperatures, the three iron cation sites of nonstoichiometric and iron-deficient wüstite can now be assigned (Figure 1A) [50]. The mixed valence of the iron phase originates from the variable occupancy of octahedral and tetrahedral sites [51], and as such, the relative ratio of the three sites can vary between certain boundaries [52]. The co-existence of the Hägg carbide phase was determined from three overlapping sextuplets with lower magnetic fields of 25.6, 21.2 and $11.1 \mathrm{~T}[20,53]$. The spectra originate from the three different sites in the $\chi-\mathrm{Fe}_{5} \mathrm{C}_{2}$ lattice, where the carbon atom is in the center of a triangle-based 

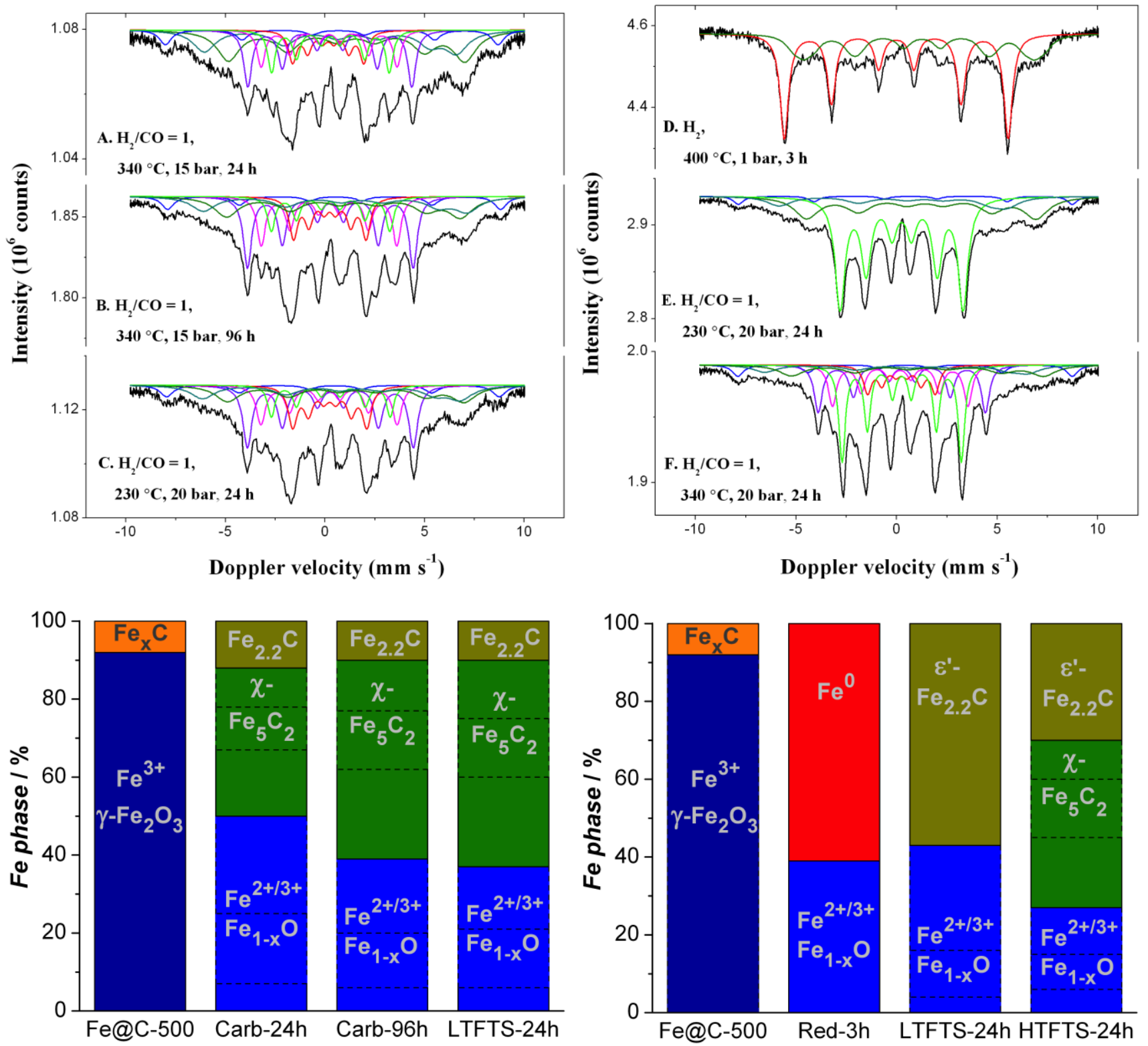

Figure 1 Mössbauer spectra of Fe@C-500 measured at $4.2 \mathrm{~K}$ after carburization $(A, B)$ and subsequent LTFT conditions (C); and after reduction (D), subsequent LTFT conditions (E) and additional HTFT (F). The bar graphs represent the spectral contributions of iron phases determined by the relative absorption areas.

prism containing six iron atoms [20]. After $24 \mathrm{~h}$ under HTFT conditions, circa half of the iron oxide has been converted into carbide, and carburization into $\chi$ - $\mathrm{Fe}_{5} \mathrm{C}_{2}$ continuously increases in time (Figure 1B). In addition to the Hägg carbide phase, a minor contribution of hexagonal iron carbide was found. After $96 \mathrm{~h}$ of in situ carburization, $63 \pm 3 \%$ of the iron phase has carburized into Hägg carbide, decreasing when switching to LTFT conditions (Figure 1C). The degree of carburization remains virtually unchanged (64 $\pm 3 \%$ ) after $24 \mathrm{~h}$ under LTFT conditions (Table S3). 
The hydrogen treatment of Fe@C-500 at $400{ }^{\circ} \mathrm{C}$ renders a clear degree of reduction in the sample (Figure 1D, Figure S4). The sextuplet observed at $4.2 \mathrm{~K}$, without relative isomer shift and a hyperfine field around 34.6 T, is typically assigned to ferrite $(\alpha-\mathrm{Fe})[21,54]$. The measurements at room temperature reveal that half of the metallic iron contributions originate from a poorly resolved signal around the central region, indicating that a large amount of the nanoparticles is present as very small superparamagnetic species. The remainder of the iron phase contains contributions from $\mathrm{Fe}^{2+}$ and $\mathrm{Fe}^{3+}$, which are attributed to the wüstite phase $\left(\mathrm{Fe}_{1-x} \mathrm{O}\right)$. The degree of reduction under hydrogen atmosphere after $3 \mathrm{~h}$ at $400{ }^{\circ} \mathrm{C}$ can be estimated to $61 \%$ (Table S3). The spectra obtained at room temperature after $24 \mathrm{~h}$ of LTFT are of a different nature. It seems however, that the oxide phase has not undergone much change, as it maintains an identical isomer shift and only a slight change in the quadrupole splitting is observed (Figure S4, Table S2). The cryogenic measurements confirm the presence of the three $\mathrm{Fe}_{1-\mathrm{x}} \mathrm{O}$ spectra, with isomer shifts between 0.56 and $1.33 \mathrm{~mm} \mathrm{~s}^{-1}$ and significant quadrupole splitting, values that are much different from the initial $\mathrm{Fe}_{2} \mathrm{O}_{3}$ phase (Table S3). Moreover, the metallic iron contribution has disappeared completely and turned into hexagonal iron carbide $\left(\varepsilon^{\prime}-\mathrm{Fe}_{2.2} \mathrm{C}\right)$, as a sextuplet with a significant isomer shift of $0.24 \mathrm{~mm} \mathrm{~s}^{-1}$ and much lower hyperfine field of $19.0 \mathrm{~T}$ has been measured [22, 26,55]. Comparison of the spectral contributions of the both phases confirm that the metallic iron has been fully converted to single-phase hexagonal iron carbide, as $61 \pm 3 \% \varepsilon^{\prime}$-carbide is obtained compared to $57 \pm 3 \%$ metallic iron (Figure 1E).

Additionally, in situ reduction was carried out for the Fe@C-600 sample, to establish whether differences in activation are obtained due to the larger nanoparticle size of $6 \mathrm{~nm}$ compared to $3.6 \mathrm{~nm}$ of Fe@C-500. Following reduction at $400{ }^{\circ} \mathrm{C}$, the degree of reduction of Fe@C-600 was found very similar to Fe@C-500, with 56 \% somewhat lower than 61 \% for the latter (Figure S5). Nonetheless, the steady-state carbide phase contribution of the catalyst with $6.0 \mathrm{~nm}$ iron nanoparticles was remarkably higher, with an $\varepsilon^{\prime}-\mathrm{Fe}_{2.2} \mathrm{C}$ spectral contribution of $68 \%$, compared to $59 \%$ for $3.6 \mathrm{~nm}$ iron nanoparticles. In addition to the $\varepsilon^{\prime}-\mathrm{Fe}_{2.2} \mathrm{C}$ phase, the larger particles rendered the onset of a secondary carbide phase. Even though the overlap greatly hindered the fitting procedure, additional sextuplets at $4.2 \mathrm{~K}$ could be assigned at isomer shifts between $0.18-0.22 \mathrm{~mm} \mathrm{~s}^{-1}$, while a magnetic field of 25.9 T was obtained for the sextuplet with the highest isomer shift, indicative of the presence of $\chi$ - $\mathrm{Fe}_{5} \mathrm{C}_{2}$ (Table S4) However, the room temperature spectra provided a hyperfine field value of $23 \mathrm{~T}$, which can be ascribed to $\varepsilon-\mathrm{Fe}_{2} \mathrm{C}$ (Table S5). The crude fit provided a value of $11 \pm 3 \%$ spectral contribution of this tentative phase after $24 \mathrm{~h}$ of LTFT under 20 bar equimolar syngas. Nevertheless, the comparison of the spectral contributions of Fe@C-500 and Fe@C-600 after LTFT shows that the $\varepsilon^{\prime}-\mathrm{Fe}_{2.2} \mathrm{C}$ is produced on the two reduced catalysts comprising different particle sizes (Figure S6 and Table 2). The spectra of the Fe@C-500 catalyst obtained after $24 \mathrm{~h}$ under HTFT conditions, following the LTFT measurements, demonstrate the evolution of the Hägg carbide at the expense of both the 
Table 2 Mössbauer derived iron carbide phases from Fe@C catalysts under reduction or carburization activation, balance of iron phase is wüstite $\mathrm{Fe}_{1-\mathrm{O}} \mathrm{O}$.

\begin{tabular}{lll}
\hline Fe@C & Activation $^{[a]}$ & LTFT $^{[b]}$ \\
\hline $500-$ Red & $60 \% \alpha-\mathrm{Fe}$ & $59 \% \varepsilon^{\prime}-\mathrm{Fe}_{2.2} \mathrm{C}$ \\
$500-\mathrm{Carb}$ & $54 \% \chi-\mathrm{Fe}_{5} \mathrm{C}_{2}, 9 \% \varepsilon^{\prime}-\mathrm{Fe}_{2.2} \mathrm{C}$ & $56 \% \chi-\mathrm{Fe}_{5} \mathrm{C}_{2}, 8 \% \varepsilon^{\prime}-\mathrm{Fe}_{2.2} \mathrm{C}$ \\
$600-$ Red & $56 \% \alpha-\mathrm{Fe}$ & $68 \% \varepsilon^{\prime}-\mathrm{Fe}_{2.2} \mathrm{C}, 11 \% \chi-\mathrm{Fe}_{5} \mathrm{C}_{2}{ }^{*}$ \\
\hline
\end{tabular}

Data obtained from Mössbauer spectroscopy at $4.2 \mathrm{~K}$ after [a] reduction or carburization treatment, $3 \mathrm{~h}$ under atmospheric hydrogen at $400{ }^{\circ} \mathrm{C}$ and $96 \mathrm{~h}$ under 15 bar equimolar $\mathrm{H}_{2} / \mathrm{CO}$, respectively, and [b] after $24 \mathrm{~h}$ low temperature Fischer-Tropsch synthesis conditions of 20 bar equimolar $\mathrm{H}_{2} / \mathrm{CO}$ at $230{ }^{\circ} \mathrm{C}$. ${ }^{*}$ Tentative.

hexagonal carbide and oxide phase (Figure 1F). The cryogenic temperature measurements show the additional contributions of the three sites of Hägg carbide at higher velocities, and the relative spectral contribution of $43 \%$ indicates that over $50 \%$ of the $\varepsilon^{\prime}-\mathrm{Fe}_{2.2} \mathrm{C}$ is converted to $\chi$ - $\mathrm{Fe}_{5} \mathrm{C}_{2}(\mathrm{Table}$ S3). In addition, the HTFT conditions also carburize part of the oxide phase, about $27 \%$ of spectral contribution from wüstite is present after $24 \mathrm{~h}$ of $\mathrm{HTFT}$, indicating that $37 \%$ of $\mathrm{Fe}_{1-\mathrm{x}} \mathrm{O}$ is converted toward $\chi-\mathrm{Fe}_{5} \mathrm{C}_{2}$. A very similar trend is obtained for the HTFT measurements of Fe@C-600 subsequently after the LTFT reaction, where $32 \%$ of the spectral area is assigned to $\varepsilon^{\prime}-\mathrm{Fe}_{2.2} \mathrm{C}$ and $38 \%$ to $\chi-\mathrm{Fe}_{5} \mathrm{C}_{2}$. This phase transition is in sharp contrast to the stable Hägg carbide phase under LTFT conditions, which is obtained after carburization under HTFT conditions. It is notable that the resulting coexistence of carbide phases of these reduced and interconverted catalysts under HTFT is very similar to the spectral composition of in situ experiments on reduced Fe@C-600 that was directly exposed to HTFT conditions [45]. The $75 \%$ metallic iron was transformed into $27 \% \varepsilon^{\prime}-\mathrm{Fe}_{2.2} \mathrm{C}$ and $67 \% \chi-\mathrm{Fe}_{5} \mathrm{C}_{2}$ after just $5 \mathrm{~h}$ under equimolar syngas at $340{ }^{\circ} \mathrm{C}$ and 15 bar. Even though singlephase carbides could not be synthesized through the abovementioned protocol, these results together with the associated catalytic data under HTFT further deepen the discussion on the activity and stability of iron carbides in the Fischer-Tropsch performance testing section.

The abovementioned measurements demonstrate that carbide-phase interconversion is related to the change in FTS conditions. Indeed, significant $\varepsilon^{\prime}-\mathrm{Fe}_{2.2} \mathrm{C}$ carbide interconversion is measured which is associated with carbon diffusion through the lattice and crystal deformation. Therefore, both the rate and degree of interconversion may very well be dependent on the particle size and degree of carburization of the initial iron nanoparticle. However, no significant difference was observed in the 
degree of carburization for Fe@C-500 and 600, while the interconversion toward $\chi-\mathrm{Fe}_{5} \mathrm{C}_{2}$ phase was slightly more pronounced on the former catalyst (Figure S6). Hence, it is likely that either a metastable equilibrium was achieved, or that the incremental interconversion in the deeper crystallite layers is kinetically limited by the diffusion of carbon. The trend of the developing surface carbide phase is in agreement with the carburization experiments on the fresh catalysts, where the oxide phase is gradually converted toward Hägg carbide over a period of many hours. Thus, the carburization kinetics of iron oxide, with respect to metallic iron, are several orders of magnitude slower.

In addition to the elucidation of the iron phases, the Mössbauer measurements at different temperatures enabled the calculation of the Debye temperatures for the various iron phases (Figure 2). The Debye temperature is, by approximation, proportional to the density of atoms per volume considered [56]. It is therefore considered a measure for the bond strength of the metal within the surrounding lattice and in traditional view, related to the hardness of a crystal. The logic of this interpretation is reflected by remarkably low Debye temperatures in the range of $45-170 \mathrm{~K}$ for highly porous MOFs and coordination polymers, in which the metal atoms are localized in molecular clusters of ionic character. The metal-metal distance and their spatial distribution greatly influence the Debye temperature, as these parameters direct the number density of the structure. The increase in the Debye temperature of Zn-MOF-74 compared to Zn-MOF-5, $170 \mathrm{~K}$ against $102 \mathrm{~K}$, respectively, is explained by the far longer and flexible linker in the latter framework and the resulting increase in separation of the metal clusters $[57,58]$. The same trend holds for MOFs comprising other metals and linkers as structural building blocks. The large-cage Gd-NBDC MOF consists of diatomic gadolinium units connected through six amino-benzenedicarboxylate linkers with Gd-Gd distances of 4.1 $\AA$ in the cluster and far larger three-dimensional spacing in the range of 10.5-12.1 $\AA$ [59]. On the other hand, the dense gadolinium-formate MOF is built up of continuous chains of nine-coordinated gadolinium ions bridged by three shared oxygen atoms of the formate ligands, resulting in Gd-Gd distances of $4.0 \AA$ in the chains and $6.2 \AA$ through the linkers [60]. Not surprisingly, the Debye temperature of Gd-NBDC of $45 \mathrm{~K}$ is far lower than the value of $168 \mathrm{~K}$ obtained for the Gd-formate MOF. These Debye temperatures, however, are in sharp contrast with conventional metals and metal oxides, as the values for bulk compounds are considerably higher. In the case of ferrite and magnetite these values increase to about 420-476 and 505-588 K, respectively [61-63]. The Debye temperature is therefore a good indication for the degree of interaction between the atoms in the different phases under consideration. 

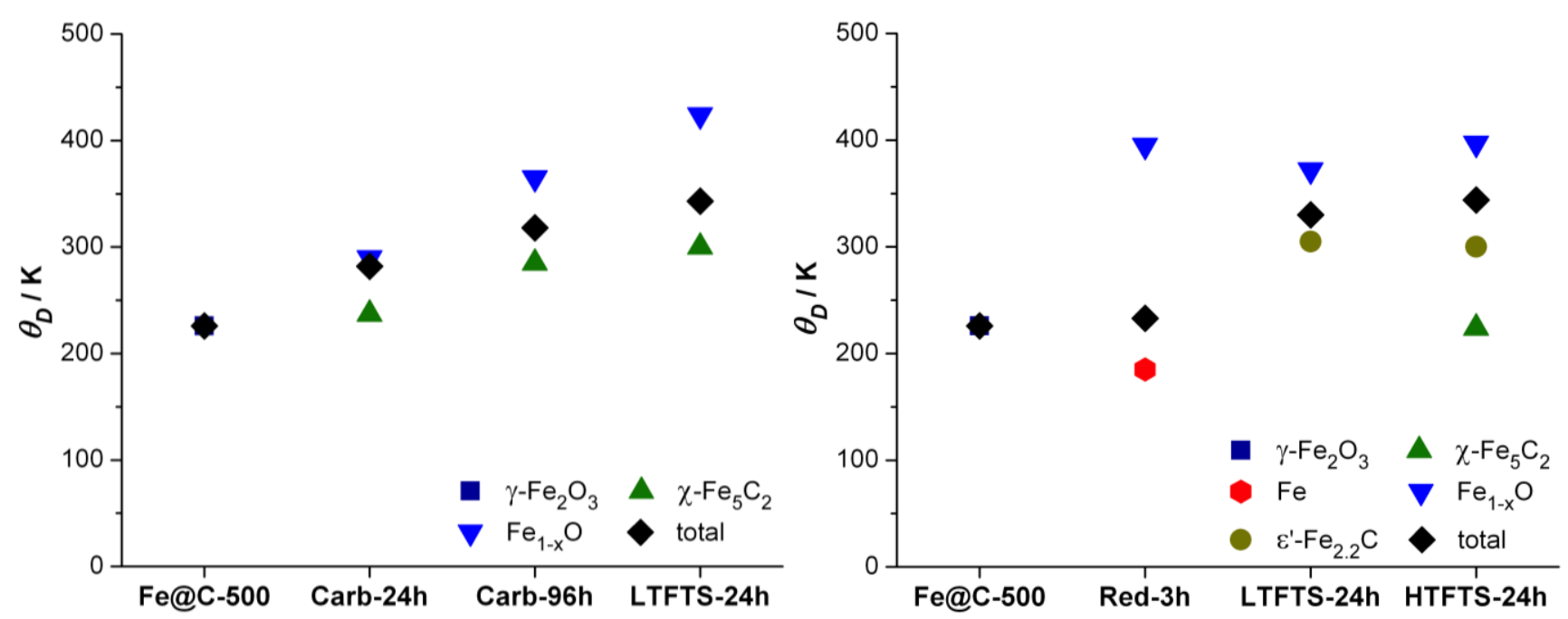

Figure 2 Debye temperatures of the iron phases in carburized Fe@C-500 and reduced Fe@C-500, following activation and FTS conditions.

Hence, the values of $226 \mathrm{~K}$ and $238 \mathrm{~K}$ for the fresh Fe@C-500 and Fe@C-600 catalysts are quite striking (Table A5.6). These Debye temperatures represent a very diffuse, perhaps even quasicrystalline, system of iron oxide nanoparticles that is clearly derived from the atomically dispersed iron of the MOF precursor. The subsequent carburization of the Fe@C-500 catalyst produces the $\chi-\mathrm{Fe}_{5} \mathrm{C}_{2}$ carbide phase, and its Debye temperature gradually increases over time to $300 \mathrm{~K}$ after $24 \mathrm{~h}$ of LTFT reaction (Figure 5.2). The reduction of Fe@C-500 leads to the formation of metallic iron with an even lower Debye temperature than the starting oxide of $185 \mathrm{~K}$, whereas the value for wüstite reaches $395 \mathrm{~K}$. The decrease in Debye temperature of metallic iron with respect to the initial oxide, in addition to the large difference between the two Debye temperatures and moreover, the large variation in the ratio to which extent bulk phase behavior value is achieved $(41 \pm 3 \%$ for Fe and $76 \pm 4 \%$ for $\mathrm{Fe}_{1-\mathrm{x}} \mathrm{O}[64]$ ), indicates that metallic iron is formed as a surface layer on top of the iron oxide that possibly segregates in part from the bulk (Figure 5.2). The following exposure to LTFT conditions resulted in the formation of $\varepsilon^{\prime}-\mathrm{Fe}_{2.2} \mathrm{C}$ carbide with a Debye temperature of $305 \mathrm{~K}$, while only minor change was observed in $\mathrm{Fe}_{1-\mathrm{x}} \mathrm{O}$. The Debye temperatures of the two types of iron carbides in Fe@C calculated from Mössbauer spectroscopy are nearly one third lower than theoretical estimates for bulk carbide crystals [65]. Hence, the lower bond strengths associated with a decrease in the Debye temperatures suggest a higher presence of crystal defects or lower coordination sites, related to the presence of surface atoms. Comparison of the two Debye temperatures and the degree of carburization for the two activation methods, $300 \mathrm{~K}$ for $56 \% \chi-\mathrm{Fe}_{5} \mathrm{C}_{2}$ and $305 \mathrm{~K}$ for $59 \% \varepsilon^{\prime}-\mathrm{Fe}_{2.2} \mathrm{C}$, thus demonstrate that two fundamentally different, though very similar, iron carbide phases have been produced. 


\subsection{Fischer-Tropsch Synthesis}

The catalytic experiments were carried out in a fixed-bed reactor under similar conditions as the Mössbauer experiments. The results of the catalytic tests are displayed in Figure 3 and Table 3, where the conversion, activity and selectivity profiles of the catalysts activated by two different methods are plotted alongside. The carburized catalysts show significant induction period during the first $70 \mathrm{~h}$ until reaching steady state, and similarly, changes are observed in the selectivity profiles of these catalysts. The methane selectivity drops under the initial $10 \%$ at values between 8 and $9 \%$, and even though possibly correlated to the conversion levels, the effect is not as profound as the $60 \%$ increase in activity. Similar marginal differences are found in the carbon dioxide selectivity. The initial values around $7 \%$ are indicative of low water-gas shift activity, to be expected at these low temperatures, and they increase only little to 8.2\% for Fe@C-500 and 9.2\% for Fe@C-600 (Table 3). These carburized catalysts display an activity of 4.02 and $3.59 \cdot 10^{-5} \mathrm{molco}_{\mathrm{Fe}}{ }^{-1} \mathrm{~s}^{-1}$, respectively, after $115 \mathrm{~h}$ of LTFT. The reduced samples reach steady-state conversion readily after the first sampling interval, maintaining identical activity and selectivity profiles during $119 \mathrm{~h}$ reaction time. In contrast to the outstanding stability of reduced Fe@C-500 over the entire time on stream, the Fe@C600 catalyst initially shows slight deactivation but stabilizes and also reaches steady-state operation. The selectivity of Fe@C-600 toward methane and carbon dioxide is however, very similar to the initial values. After $100 \mathrm{~h}$, both catalysts show constant activity and selectivity to methane and carbon dioxide, indicating that no further reduction or carburization of the iron phase is taking place.

The observation that the carburization of $\alpha$-Fe toward $\varepsilon^{\prime}-\mathrm{Fe}_{2.2} \mathrm{C}$ takes place within the hour, is in agreement with the carbon diffusion prevalence in the iron lattice over FTS kinetics on the surface, as the carburization kinetics of ferrite are in the order of catalytic turnover numbers [27, 40]. The conversion levels obtained after one hour are maintained even after $100 \mathrm{~h}$, indicative of a highly stable catalyst absent from sintering and inactive carbon deposition. The Mössbauer data after $24 \mathrm{~h}$ LTFT indicates that the hexagonal iron carbide is a very stable phase under the applied high carbon chemical potential, and moreover, that it can be obtained only by carburizing very small metallic iron nanoparticles. The conversion data during $140 \mathrm{~h}$ carburization (Figure 4) demonstrates that the increase in conversion is parallel to the carburization of the fresh catalyst toward $\chi-\mathrm{Fe}_{5} \mathrm{C}_{2}$. The notable resemblance of the shapes indicates that carburization of iron oxide under HTFT conditions is very slow and that the equilibrium phase is reached much later than in the carburization of metallic iron, as the reaction rate reaches steady state after $140 \mathrm{~h}$. Moreover, the shape of the conversion profile and degree of carburization suggest that the surface carbide acts as a gateway, moving the dissociated carbon down into the bulk of the iron oxide particle. Therefore, the rate of diffusion controls the rate of reaction by modifying the active site density by effectively lowering the surface 

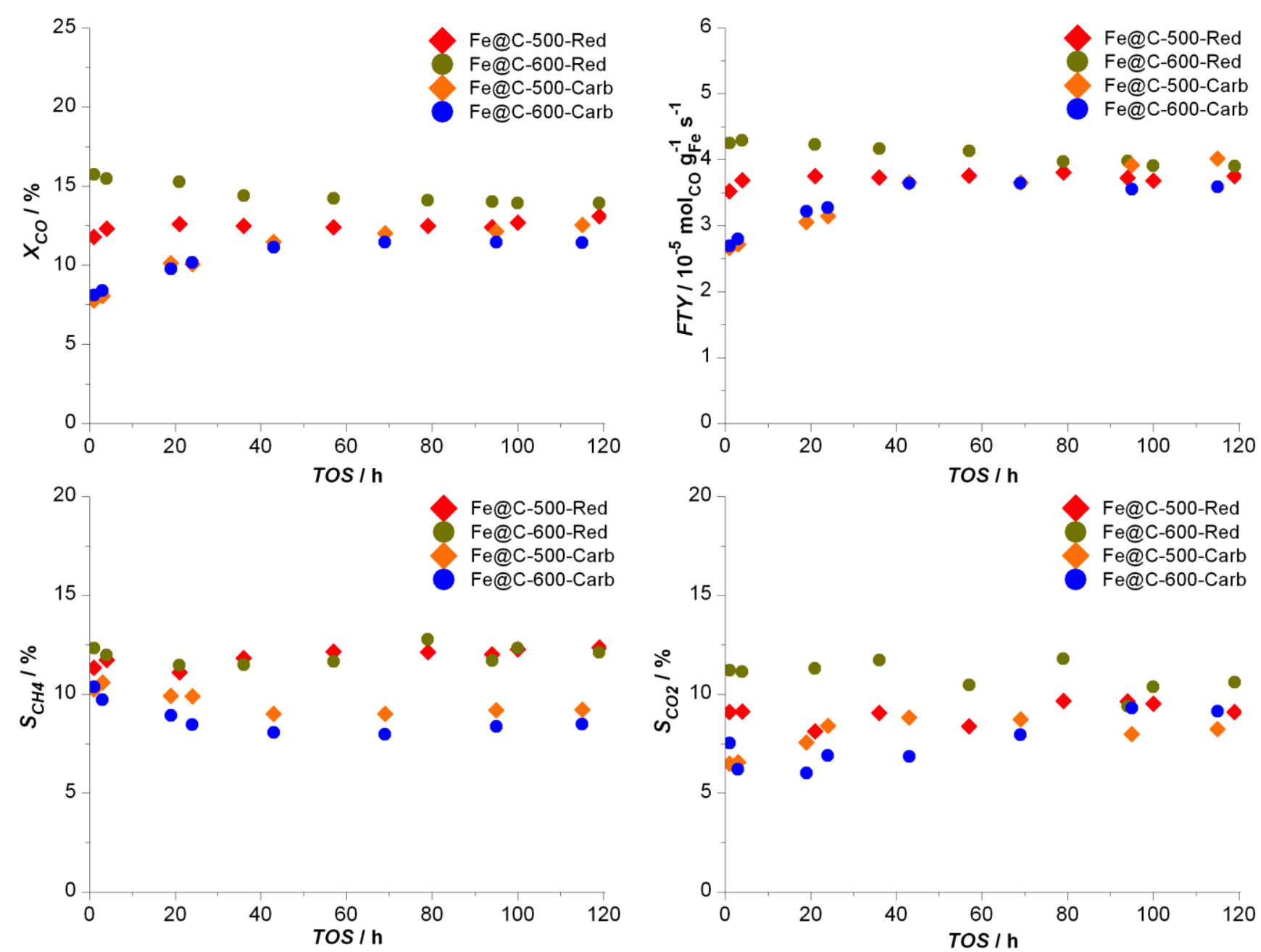

Figure 3 Fe@C-500 and Fe@C-600 catalytic testing results under LTFT conditions $\left(230{ }^{\circ} \mathrm{C}, 20\right.$ bar, $\mathrm{H}_{2} / \mathrm{CO}=1$, $W H S V=55 \mathrm{dm}^{3} \mathrm{~Hz} / \mathrm{CO}_{\mathrm{Fe}}{ }^{-1} \mathrm{~h}^{-1}$, displaying the conversion profiles $\left(X_{C O}\right)$, iron time yield $(F T Y)$, methane selectivity $\left(\mathrm{S}_{\mathrm{CH} 4}\right)$ and carbon dioxide selectivity $\left(\mathrm{S}_{\mathrm{CO} 2}\right)$.

Table 3 Catalytic performance of reduced and carburized Fe@C under LTFT conditions of $230{ }^{\circ} \mathrm{C}, 20$ bar, $\mathrm{H}_{2} / \mathrm{CO}=1, W H S V=55 \mathrm{dm}^{3} \mathrm{H}_{2} / \mathrm{CO}_{\mathrm{Fe}}{ }^{-1} \mathrm{~h}^{-1}$, product selectivities obtained between 94-99 $\mathrm{h}$ time on stream.

\begin{tabular}{llllllll}
\hline Fe@C & $X_{\mathrm{CO}} / \%$ & $\left.F T Y /{ }^{*}\right]$ & $S_{\mathrm{CH} 4} / \mathrm{C} \%$ & $S_{\mathrm{CO} 2} / \mathrm{C} \%$ & $S_{\mathrm{C} 2 \mathrm{C} 4} / \mathrm{C} \%$ & $S_{\mathrm{C} 5+} / \mathrm{C} \%$ & $\alpha /-$ \\
\hline 500 -Carb & 12.5 & 4.02 & 9.2 & 8.2 & 23.3 & 59.3 & 0.72 \\
600-Carb & 11.4 & 3.59 & 8.5 & 9.2 & 22.0 & 60.3 & 0.71 \\
$500-$ Red & 13.1 & 3.75 & 12.4 & 9.1 & 27.6 & 50.9 & 0.68 \\
$600-$ Red & 13.9 & 3.90 & 12.1 & 10.6 & 28.2 & 49.1 & 0.67 \\
\hline * FTY, iron time yield, catalytic activity expressed as $10^{-5}$ mol carbon monoxide converted to hydrocarbon
\end{tabular}
products per gram of iron per second, explicitly excluding carbon dioxide selectivity. 


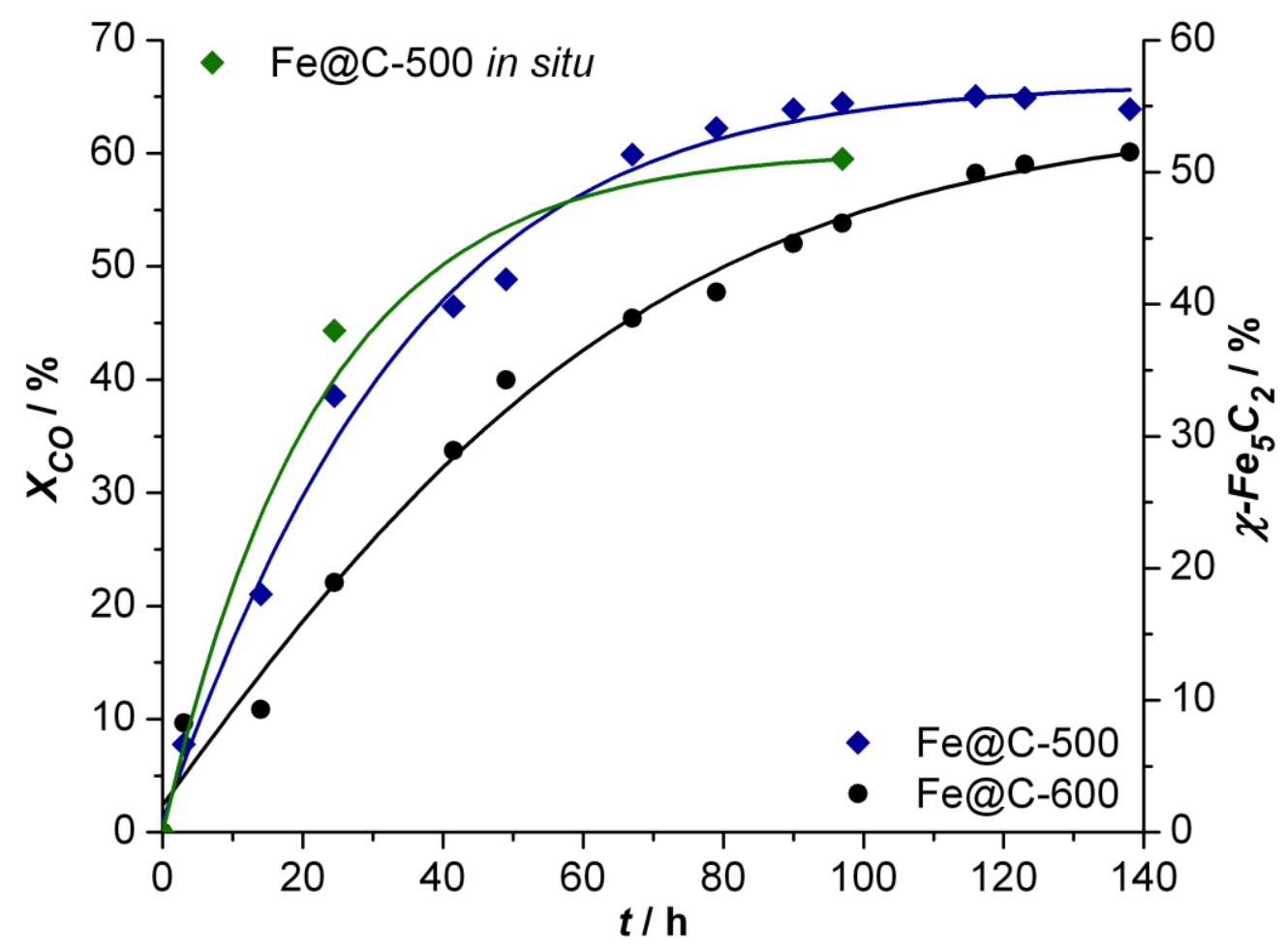

Figure 4 Conversion profiles obtained during catalytic testing of Fe@C-500 and -600 while carburizing the fresh catalysts under $340^{\circ} \mathrm{C}, 15 \mathrm{bar}, \mathrm{H}_{2} / \mathrm{CO}=1$, plotted alongside the spectral contribution of Hägg carbide of Fe@C-500 during carburization under similar conditions in the in situ Mössbauer cell.

carbide concentration. The process of reaching constant rates of reaction and degree of carburization is increased with two orders of magnitude over the iron oxides compared to metallic iron catalysts.

The dimension of the activity was casted into moles of carbon monoxide converted toward hydrocarbon products per hour, in order to compare the Fe@C results to both iron and cobalt literature values (Table S7). The activity of Fe@C catalysts at $230{ }^{\circ} \mathrm{C}$ is very impressive in view of the range of lower values obtained at higher temperatures for different iron catalysts. The majority of the iron catalysts remain below the activity values reported for Fe@C up to temperatures of 260$270{ }^{\circ} \mathrm{C}$, where the activity increases up to a twofold for iron catalysts supported on silica and carbon nanotubes. These results demonstrate that the dispersion of iron is by far better achieved and maintained on large surface-area supports with little metal-support interaction, of which MOF-derived catalysts are the perfect example. The exception to this trend in activity and temperature is a recently reported skeletal iron catalyst, derived from an iron-alumina template that is subsequently alkali leached. The high dispersion and accessibility of the iron nanoparticles and the lower operation temperature of $200{ }^{\circ} \mathrm{C}$ render the formation of $\varepsilon-\mathrm{Fe}_{2} \mathrm{C}$. The activity of this catalyst is slightly lower, however, direct comparison is not applicable to this batch operational mode with an initial pressure of 50 bar with conversions calculated relative to the starting pressure of 30 bar (Scheme S1) [66]. The Fe@C activity compared to cobalt catalysts is similar or slightly worse, as several outliers to higher 
activity are obtained for cobalt in the temperature range of $190-240{ }^{\circ} \mathrm{C}$. Nevertheless, it is noteworthy that the activity of stable iron catalysts is comparable to well-dispersed cobalt catalysts.

The comparison of the Fe@C catalysts to iron supported on carbon-nanotubes under similar LTFT conditions $\left(220{ }^{\circ} \mathrm{C}, 25\right.$ bar and $\mathrm{H}_{2} / \mathrm{CO}=2$ and $\left.X_{C O}=5-15 \%\right)$ yields quite an analogous product slate. A carbon dioxide selectivity between $6.9-19.5 \%$, a $\mathrm{C}_{3}-\mathrm{C}_{7}$ alpha around $0.64-0.67$, and an olefin content in the range of $40-70 \%$ are in good agreement with our results [67]. Studies on coprecipitated iron-zinc catalysts impregnated with $\mathrm{Cu}, \mathrm{K}$, and $\mathrm{Ru}$ under LTFT conditions similar to the present research $\left(235^{\circ} \mathrm{C}, 21.4\right.$ bar and $\mathrm{H}_{2} / \mathrm{CO}=2$ and $\left.X_{C O}=13-16 \%\right)$ demonstrate that extensive promotion can greatly increase the chain growth probability, decreasing the methane selectivity below $3 \%$ and increasing the $\mathrm{C}_{5+}$ selectivity above $85 \%$ [68]. The significant improvement in long-chain hydrocarbon selectivity has to be interpreted in terms of fundamental changes in physiochemical properties, rather than minor changes in hydrogenation ability from a different active carbide phase. These profoundly promoted iron catalysts comprise an even higher wax selectivity than conventional cobalt supported on zirconia-alumina catalysts, which achieve a methane selectivity of $7.9 \%, \mathrm{C}_{2}-\mathrm{C}_{4}$ selectivity of $13.7 \%$ and a $\mathrm{C}_{5_{+}}$selectivity of $78.4 \%$ under comparable LTFT conditions $\left(240{ }^{\circ} \mathrm{C}, 20.7 \mathrm{bar}, \mathrm{H}_{2} / \mathrm{CO}=1\right)$ [69]. It is remarkable that both the FTS and WGS rates over the Fe@C catalysts under LTFT conditions are nearly identical as those over Co@C catalysts derived from ZIF-67 and MOF-74 (Table S7). However, the Fe@C methane selectivity of $\sim 10 \%$ is superior to the $\sim 20 \%$ of the cobalt catalysts [70]. The increased hydrogenation ability may however, be partially explained by the higher partial pressure of hydrogen (30 bar and $\mathrm{H}_{2} / \mathrm{CO}=2$ against 20 bar and $\mathrm{H}_{2} / \mathrm{CO}=1$ ), as $\mathrm{C}_{5+}$ selectivity is limited to $65 \%$ in comparison to $60 \%$ for the Fe@C counterpart. These results confirm that iron-based catalysts are exceptionally versatile and that highly dispersed samples can challenge the performance of cobalt-based catalysts.

The high stability of the catalytic performance is likely related to the nature of the Fe@C catalyst, comprising a high degree of $\mathrm{Fe}-\mathrm{C}$ interaction through its matrix that stabilizes the iron carbide phase and apparently, does not allow sintering or migration of iron clusters. Furthermore, the catalysts do not suffer from high partial pressures of water or carbon dioxide under these differential conditions at low conversion. Above critical ratios of the partial pressure of water over hydrogen $\left(p \mathrm{H}_{2} \mathrm{O} / \mathrm{pH}_{2}\right)$ and carbon dioxide over carbon monoxide $\left(p \mathrm{CO}_{2} / p C O\right)$, as derived by O'Brien et al. [36], the reaction conditions yield an atmosphere where iron oxide is the thermodynamic stable phase. However, those calculations were most likely performed using the thermodynamic equilibria values at $1000 \mathrm{~K}$ from the original book [71], shown by recalculation in Scheme S2. At relevant reaction conditions around $500 \mathrm{~K}$, the values for $-\log \left(p \mathrm{O}_{2}\right)$ are a factor of 2.5 higher, resulting in $p \mathrm{H}_{2} \mathrm{O} / \mathrm{pH}_{2}$ and $p \mathrm{CO}_{2} / p \mathrm{cO}$ ratios several orders of magnitude larger than reported. Therefore, determining the surface concentrations of water and carbon dioxide would describe the tendency of the iron phase to oxidize more realistically. However, the importance of the WGS ability on iron catalysts is underlined, as the 
$\log \left(\mathrm{pH}_{2} \mathrm{O} / \mathrm{pH}_{2}\right)$ value of iron is far higher than for cobalt catalysts, confirming that iron is inherently more prone to oxidation by water than cobalt catalysts. The same calculation for the ratio $p \mathrm{CO}_{2} / p \mathrm{CO}$ demonstrates that carbon dioxide is a substantially less oxidizing molecule than water, enhancing the catalyst stability when iron is WGS active.

The result that perhaps attracts the most attention is the methane selectivity of the reduced Fe@C samples, which is significantly higher than that of the carburized Fe@C samples. The analysis at isoconversion levels allows for a qualitative comparison of the methane selectivity between the two activation methods for the same catalysts: $\sim 9 \%$ methane for carburized samples compared to $\sim 12 \%$ methane for the reduced catalysts (Table 3). On the contrary, the activity of all catalysts is nearly equal after reaching steady-state operation. Comparing the Fe@C-500 activity under reduction and carburization, the difference is below $8 \%$, and for the Fe@C-600 it is below $9 \%$. The product distribution furthermore underlines the difference between selectivities of the carburized and reduced Fe@C catalysts. Though the calculated values for the chain growth probability are very alike, it seems that the decrease in methane selectivity for the carburized samples is related to an increase in long-chain hydrocarbon selectivity (Table 3). While the methane selectivity is about $25 \%$ lower than for the reduced samples, the relative increase in $\mathrm{C}_{2}-\mathrm{C}_{4}$ is $\sim 21 \%$ and in $\mathrm{C}_{5_{+}}$is $\sim 20 \%$. The bar graphs for the carbon selectivity in Figure $\mathbf{S 7}$ additionally demonstrate the trend toward an increase in longchain hydrocarbon selectivity for the carburized samples. This trend in selectivity suggests that the overall hydrogenation ability of the carburized catalysts is lower than that of the reduced samples. Comparison to the theoretical Flory and Schulz distributions plotted in Figure S8 displays that alpha values of $0.7 \pm 0.05$, in line with the accuracy of the calculated values from FTS experiments, indeed correspond to a methane selectivity between 7-13\%. The $\mathrm{CO}_{2}$-free methane selectivities for the four experiments are in agreement with the theoretical values, though the carburized samples comprising methane selectivities between $9-10 \%$ correspond more to alpha equal or larger to 0.7 , whereas the reduced samples with methane selectivities around $13.5 \%$ are more in the range of alpha equal or below 0.65 . Additionally, the $\mathrm{CO}_{2}$-free $\mathrm{C}_{2}-\mathrm{C}_{4}$ selectivities for all samples in the range of $24.2-31.5 \%$ are notably lower than the theoretical values, suggesting marginally higher alpha values around 0.75 for reduced samples and 0.8 for carburized samples. Comparable differences in selectivity for reduced and carburized precipitated iron catalysts were obtained by Bukur et al. in both fixed bed and slurry phase FTS experiments [34, 38]. For reduced samples, the methane selectivity was higher while a lower $\mathrm{C}_{5+}$ selectivity was obtained in comparison to carburized catalysts. The authors postulated that the surface hydrogen concentration is higher on reduced catalysts, as ferrite would possess a larger number of sites for hydrogen adsorption or enhanced hydrogen dissociation ability, therefore altering the occupation of elemental hydrogen. Hence, carburization indeed leads to increased long-chain hydrocarbon selectivity in comparison to reduction possibly by decreasing the hydrogenation ability of the surface. 

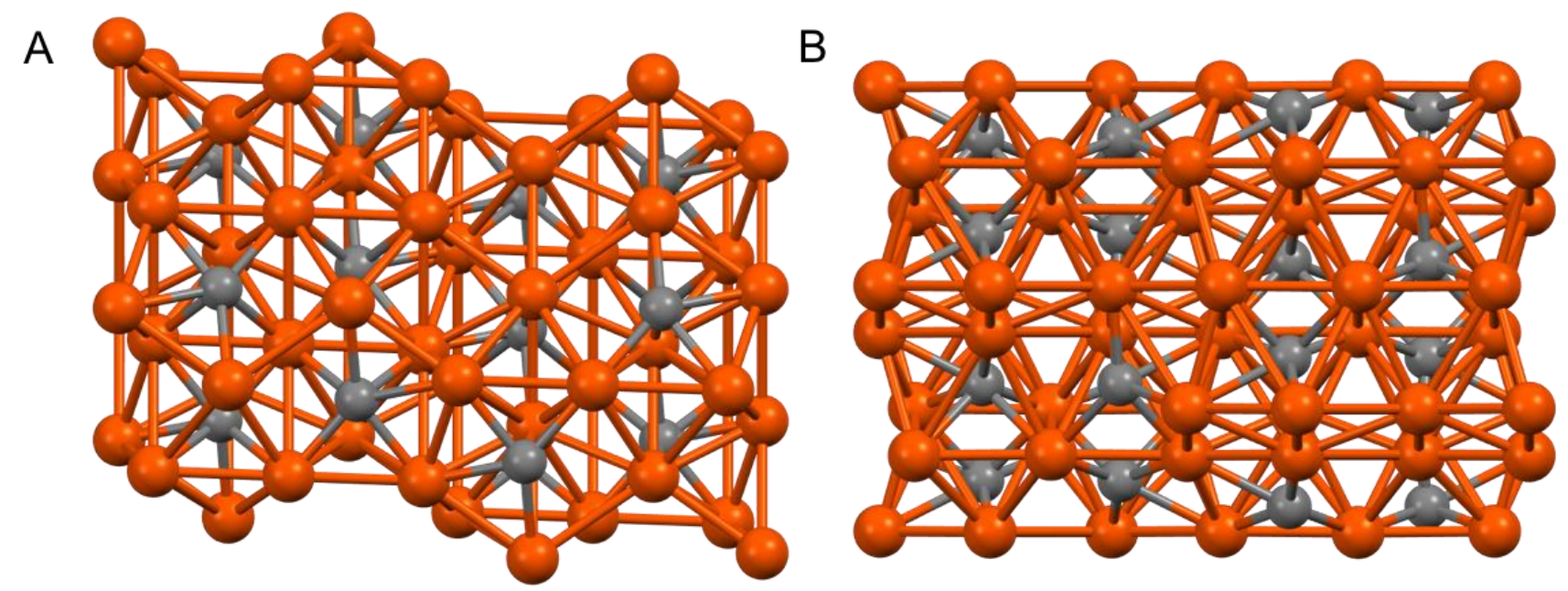

Figure 5 Crystallographic structures of $\mathbf{A}$ hexagonal carbide $\dot{\varepsilon}$ - $-\mathrm{Fe} 2.2 \mathrm{C}$ and $\mathbf{B}$ Hägg carbide $\chi-\mathrm{Fe}_{5} \mathrm{C}_{2}$ viewed along the c-axis. Iron atoms are depicted as orange spheres and carbon atoms as grey spheres [17, 72]

The key question remains why the product selectivity of the two carbide phases in Fe@C is different. Closely examining the structure of the carbides, it is observed that $\varepsilon^{\prime}-\mathrm{Fe}_{2.2} \mathrm{C}$ comprises a moderately higher atomic carbon to iron ratio of 0.45 compared to 0.4 for $\chi-\mathrm{Fe}_{5} \mathrm{C}_{2}$, and the interstitial occupation of the carbon atoms is quite different (Figure 5). The carbon atoms in the hexagonal lattice of $\varepsilon^{\prime}$ $\mathrm{Fe}_{2.2} \mathrm{C}$ are located in the octahedral site, whereas the carbon in monoclinic $\chi-\mathrm{Fe}_{5} \mathrm{C}_{2}$ is located in the trigonal prismatic interstice. This could suggest that a different active site might be built on the surface of the carbide, which possesses different electron density or exposed crystal facets. The hydrogenation ability might therefore be altered, rendering differences in the adsorption-desorption strengths or in the reaction intermediate stabilization through a different kinetic pathway. However, keeping in mind that the equal levels of activity obtained in this study suggest that the number density of these active sites is controlled by the nanoparticle size and that the nature of the active sites must be rather similar. These conclusions coincide with DFT studies on different iron carbide surfaces, demonstrating that different Hägg carbide surfaces comprise very similar surface energies [73]. Larger differences between the adsorption energy of CO exist on vacancy sites and alternative sites on the $\chi-\mathrm{Fe}_{5} \mathrm{C}_{2}$ surface, indicating that stepped and corrugated surfaces play an important role in adsorption and activation of carbon monoxide on iron carbide surfaces [74]. Furthermore, carbon monoxide adsorption on sites comprising more iron atoms displays progressively weakening of the $\mathrm{CO}$ bond with increasing number of bonds to iron atoms, suggesting the type of carbide can play a role in performance [75]. Therefore, the formation of unique iron carbide surface sites may result in intrinsic selectivity differences giving rise to a notable $25 \%$ change in hydrogenation ability. However, at this stage, it is not confirmed nor rejected that other factors than the iron nature are at play. 
Differences in selectivity between hydrogen-reduced and syngas-carburized iron catalysts are not unknown for iron catalysts [76]. However, where early Ruhrchemie studies report identical behavior in selectivity for hydrogen-reduced and syngas-carburized iron catalysts compared to Fe@C catalysts in this work, no conclusive characterization for iron dispersion, deactivation, and iron phases was reported to interpret the results with regard to the iron carbide phase [77]. Elaborate work by Bukur et al. on the effect of pretreatment conditions on the catalytic performance iron catalysts confirmed the abovementioned results [34]. The hydrogen-reduced catalysts comprised higher overall hydrogenation ability than carburized catalysts, witnessed by an increased methane production and decreased $\mathrm{C}_{5+}$ selectivity. Mössbauer characterization of the spent catalysts showed that $\varepsilon^{\prime}-\mathrm{Fe}_{2.2} \mathrm{C}$ was the dominant phase for the reduced catalysts, obtaining values between $57 \%$ and $95 \%$ of hexagonal carbide. The dominant phase of the carburized samples was Hägg carbide, with values ranging between $65 \%$ and $94 \%$ of $\chi-\mathrm{Fe}_{5} \mathrm{C}_{2}$. Whilst these results coincide with the present study, most of the samples drawn from the reactor displayed mixtures of several carbides and oxides. Furthermore, severe deactivation of the carburized samples and overall integral reactor operation with large variation in conversion over time resulted in large differences between catalyst composition and carbide phases, not allowing for an unequivocal correlation between the iron carbide phase and selectivity. Nevertheless, a more general effect of the activation method on the catalyst selectivity was established, as it was postulated that differences in selectivity originate from the change in relative hydrogen coverage obtained after reduction and carburization. The formation of metallic iron would be key to promote higher hydrogen coverage on the iron catalyst surface. The increasing coverage for hydrogen would increase stability during FTS, as less inactive carbon is deactivating the catalytic surface.

To display the subtlety of intrinsic iron carbide performance quantification, HTFT performance results of reduced Fe@C catalysts are plotted alongside those of carburized samples, where activation is directly followed by HTFT reaction conditions (Figure 6). Both the activity and selectivity of the carburized and reduced catalysts in the same particle-size range are indistinguishable under HTFT (Table S8). From the abovementioned Mössbauer analysis, it is found that Fe@C-600 carburization and HTFT after $24 \mathrm{~h}$ produces $30 \%$ of $\varepsilon^{\prime}-\mathrm{Fe}_{2.2} \mathrm{C}$ and $43 \%$ of $\chi-\mathrm{Fe}_{5} \mathrm{C}_{2}$, whereas reduction of $\mathrm{Fe} @ \mathrm{C}$ 600 and subsequent HTFT produces $27 \%$ of $\varepsilon$-Fe ${ }_{2.2} \mathrm{C}$ and $67 \%$ of $\chi$-Fe ${ }_{5} \mathrm{C}_{2}$ after just $5 \mathrm{~h}$ under equal HTFT conditions. Hence, irrespective of the activation method, the HTFT conditions result in a coexistence of carbide phases in the Fe@C catalysts. The performance results for these catalysts are unmistakably identical, now with the Hägg carbide as the dominant phase. The Debye temperature of $224 \mathrm{~K}$ for the Hägg carbide formed on the reduced Fe@C-500 catalyst (Figure 2) resembles the value for the fresh Fe@C-500 which is carburized under HTFT for $24 \mathrm{~h}$. Additionally, half of the $\varepsilon$ - $-\mathrm{Fe}_{2.2} \mathrm{C}$ carbide phase of reduced Fe@C-500 is converted to $\chi$-Fe ${ }_{5} \mathrm{C}_{2}$ under HTFT conditions, and the carburization toward Hägg carbide from the oxide phase is confirmed as well. 

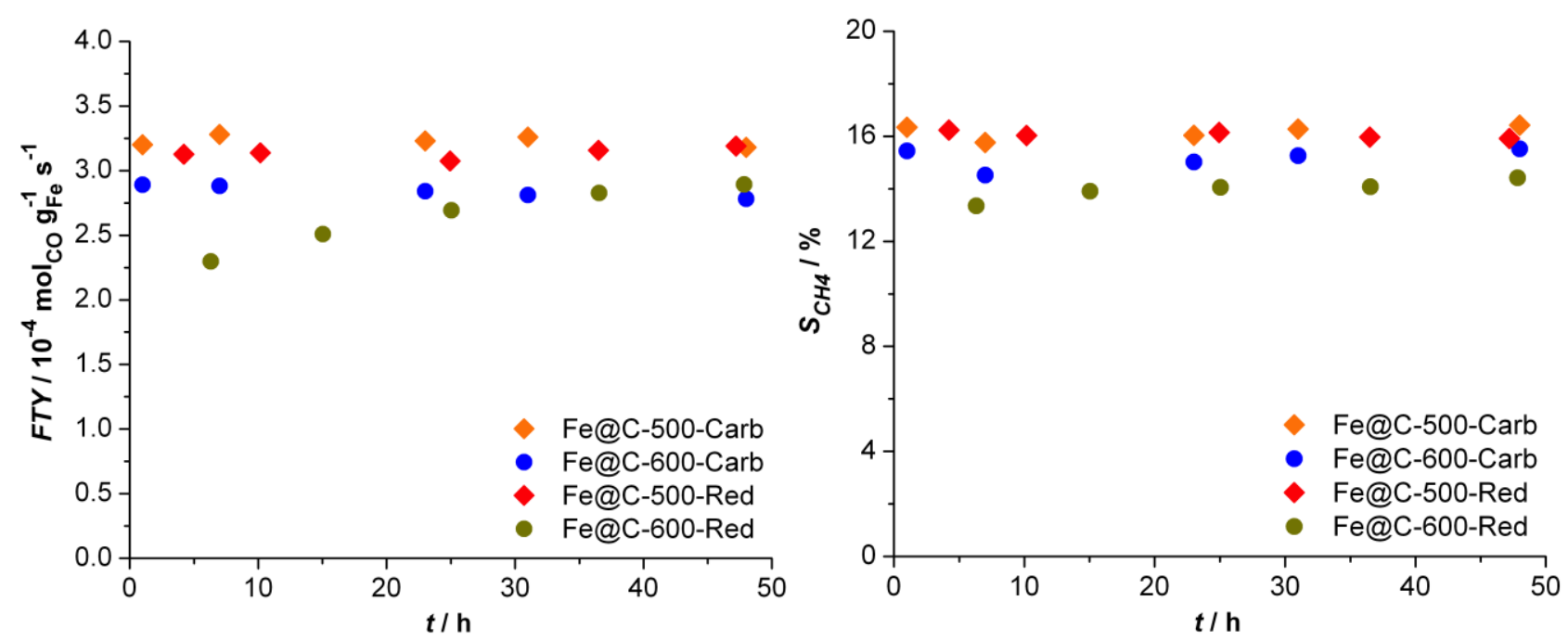

Figure 6 Fe@C-500 and Fe@C-600 catalytic testing results under HTFT conditions $\left(340{ }^{\circ} \mathrm{C}, 20\right.$ bar, $\mathrm{H}_{2} / \mathrm{CO}=1, W H S V=120 \mathrm{dm}^{3} \mathrm{H}_{2} / \mathrm{CO} \mathrm{gFe}^{-1} \mathrm{~h}^{-1}$, displaying the iron time yield $\left(F T Y\right.$ and methane selectivity $\left(S_{C H 4}\right)$.

This interconversion indicates that the carbon chemical potential of the HTFT conditions dictates the sole formation of $\chi-\mathrm{Fe}_{5} \mathrm{C}_{2}$ on the iron surface, rendering the identical performance on both catalysts now evident. The combined analysis of the two FTS temperature regimes underlines the importance of the controlled carbide phase formation and appropriate operating conditions to enable comparison of activity and selectivity. These results provide a firm basis to assign the difference in methane and long-chain hydrocarbon selectivity to the single-phase presence of $\varepsilon^{\prime}-\mathrm{Fe}_{2.2} \mathrm{C}$ and $\chi$ - $\mathrm{Fe}_{5} \mathrm{C}_{2}$.

\subsection{Transmission Electron Microscopy}

In order to rule out differences in iron carbide phases and catalytic performance originating from changes in the iron dispersion, TEM analysis is reported for the fresh and spent catalysts (Figure 7 and Figure S10). Both the fresh and spent catalysts were extremely prone to oxidation, as no carbide phases were detected after exposure to $5 \%$ oxygen in helium at room temperature. Both fresh and spent samples are characterized by a high density of spherical particles placed randomly throughout the carbon matrix. The small iron nanoparticles possess remarkably low contrast compared to the carbon matrix, in addition to the absence of lattice fringes or clear crystallite domains. Quantitative analysis established the average particle size of the fresh Fe@C-500 at $3.6 \mathrm{~nm}$, obtaining a unimodal normal distribution for the monodisperse iron (Figure S9A). Because of the pyrolysis temperature effect, as extensively investigated previously, the particle size of Fe@C600 increased to an average of $6.0 \mathrm{~nm}$ (Table 4). In addition to the high dispersion, the two catalysts comprise a very low degree of agglomerates, as only $5 \%$ of the particles is present in size above $10 \mathrm{~nm}$. Lattice fringes are only visible on the larger nanoparticles at the edges of the catalyst grains, where values of $0.246 \mathrm{~nm}$ and $0.207 \mathrm{~nm}$ are calculated for Fe@C-500, and $0.236 \mathrm{~nm}$ and $0.196 \mathrm{~nm}$ for Fe@C-600. These spacings correspond to the 311 and 400 plane of $\gamma-\mathrm{Fe}_{2} \mathrm{O}_{3}$, respectively, 
confirming the oxidized nature of the fresh samples. The electron diffraction patterns of the bulk phase show very weak and broad rings of polycrystalline iron oxides, likely because of the small average particle size of the sample (Figure S11A). Micrographs of the somewhat larger particles on the outskirts of the carbon matrix clearly show the presence of graphitic shells around the particles.

The spent analysis of the both the carburized and reduced samples show that the dispersion is very well maintained. Micrographs contain a high density of isolated nanoparticles with low contrast to the carbon matrix. Carburization of the Fe@C-500 and -600 catalysts at $340{ }^{\circ} \mathrm{C}$ for $140 \mathrm{~h}$ and additional LTFT for $100 \mathrm{~h}$ produces iron nanoparticles with average size of $4.2 \mathrm{~nm}$ and $6.5 \mathrm{~nm}$, respectively (Table 4). Compared to $3.6 \mathrm{~nm}$ and $6.0 \mathrm{~nm}$ for the fresh samples, these results are indicative of very stable catalysts, suffering from only minor particle growth during operation. Moreover, only the outskirts of the catalyst grains display particle growth, while in the bulk of the catalysts there is virtually no difference between the fresh and spent particles (Figure S10B). The high stability can be explained by the homogenous embedding of the iron nanoparticles in the carbon matrix, effectively eliminating severe sintering effects like particle migration and coalescence. Though the particle size distributions show that monodispersion is maintained, the width of the curves has broadened (Figure S9B,E). Additionally, the curves display a positive skew and are consequently better represented by a log normal fit, in contrast to the Gaussian curves of the fresh samples. These characteristics suggest that Ostwald ripening is the sintering mechanism that produces the minor increase in particle size distribution [78]. However, the typical behavior of enhanced sintering on smaller nanoparticles is applicable to the Fe@C catalysts as well, as the increase in average particle size was more profound on Fe@C-500 than on Fe@C-600 regardless of the activation protocol [79].

Reduction of Fe@C500 and -600 catalysts and subsequent LTFT reaction for $100 \mathrm{~h}$ produces very similar particle size distributions, yet comprising slightly larger average sizes: $4.4 \mathrm{~nm}$ and $6.9 \mathrm{~nm}$, respectively (Table 4). No additional differences between reduced and carburized samples are observed from the images, except for a small increase in the average particle size of the reduced catalyst. Moreover, the extraction of the modal value from the histograms, i.e., the most frequent particle size disregarding the skew in the log normal distributions, confirms identical particle sizes for the different activation methods (Figure S9C,F). Furthermore, the electron diffraction patterns of spent samples are quite diffuse like the fresh samples, where the polycrystalline $\gamma-\mathrm{Fe}_{2} \mathrm{O}_{3}$ phase is now identified due of the presence of four diffraction rings with corresponding $d$-spacing (Figure S11B). Additionally, the very small number of bright spots present in the ring pattern confirm that agglomeration is effectively hindered on Fe@C catalysts. Thus, the iron dispersion was maintained after activation and prolonged hours of FTS operation, without a substantial increase in average 


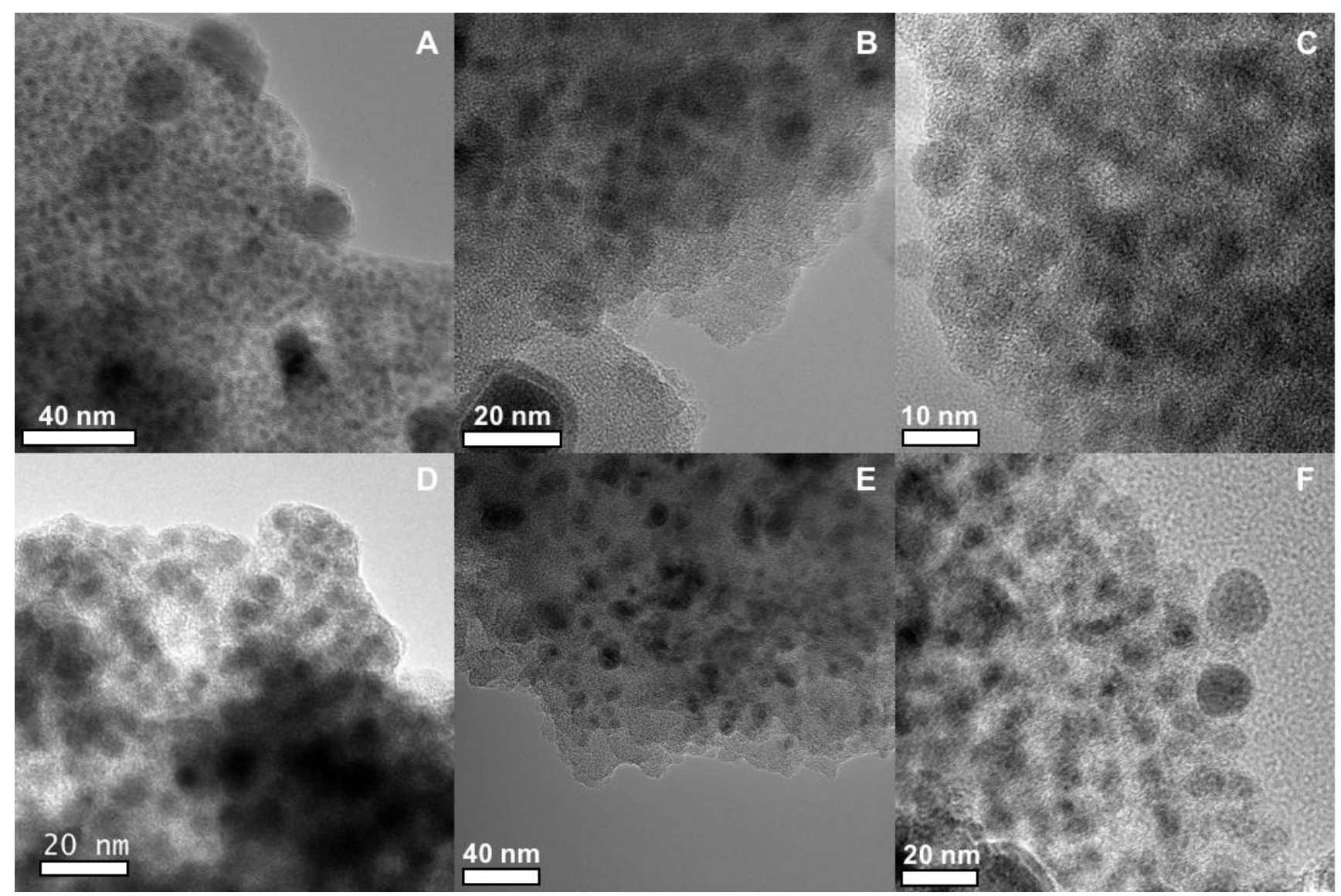

Figure 7 Micrographs of fresh Fe@C-500 (A, top row) and Fe@C-600 (D, bottom row) catalysts, and images of spent catalysts after $140 \mathrm{~h}$ carburization and $120 \mathrm{~h} \mathrm{LTFT} \mathrm{(B,E)} \mathrm{and} \mathrm{after} 3 \mathrm{~h}$ reduction and $120 \mathrm{~h} \mathrm{LTFT} \mathrm{(C,F)}$ under different magnification. The small iron nanoparticles embedded in the carbon matrix are visible as lowcontrast dark circles, in comparison to the lighter carbon matrix.

particle size. This profound stability allows measuring intrinsic activity and selectivity without the effects of differences in catalytic surface area and particle morphology effects.

Table 4 Average particle size of pre- and post-reaction Fe@C catalysts after $120 \mathrm{~h}$ LTFT reaction using different activation procedures.

\begin{tabular}{|c|c|c|c|c|c|}
\hline \multirow{2}{*}{ Catalyst } & \multirow{2}{*}{$\begin{array}{l}\text { Fresh } \\
\text { Average / nm }\end{array}$} & \multicolumn{2}{|c|}{ Carburized } & \multicolumn{2}{|c|}{ Reduced } \\
\hline & & Average / nm & Mode / nm & Average / nm & Mode / nm \\
\hline Fe@C-500 & $3.6 \pm 0.1 \mathrm{~nm}$ & $4.2 \pm 0.3$ & $4.0 \pm 0.5$ & $4.4 \pm 0.5$ & $4.0 \pm 0.5$ \\
\hline Fe@C-600 & $6.0 \pm 0.2 \mathrm{~nm}$ & $6.5 \pm 0.5$ & $7.0 \pm 0.5$ & $6.9 \pm 0.5$ & $7.0 \pm 0.5$ \\
\hline
\end{tabular}


Differences in selectivity arising from the change in relative coverage because of particle size effects can be investigated looking at the catalytic performance of the Fe@C-500 and Fe@C-600. The latter comprises a much larger average particle size of the spent catalysts between 6.5-6.9 nm compared to the smaller average particle size of spent Fe@C-500 between 4.2-4.4 nm. Isotopic labelling studies on Fe-CNT under HTFT conditions display that higher $\mathrm{CH}_{\mathrm{x}}$ coverages and lower $\mathrm{H}$ coverages on Hägg carbides are found for increasing particles sizes [80]. However, the difference in hydrocarbon selectivity was only visible with a change in activation method for both catalysts comprising different particle size (Figure 3 and Table 3). Hence, it is concluded that the variation in product selectivity is associated with the difference in iron carbide phase, effectively ruling out particle size effects.

\section{Conclusions}

In this work, Fe@C catalysts were used to produce single-phase iron carbides in a controlled manner for their performance assessment in Fischer-Tropsch synthesis. Postulates from literature indicating that supported, highly-dispersed iron catalysts are needed to stabilize a high degree of carbon incorporation into the lattice are confirmed, as single phase $\varepsilon^{\prime}-\mathrm{Fe}_{2.2} \mathrm{C}$ and $\chi$ - $\mathrm{Fe}_{5} \mathrm{C}_{2}$ were synthesized from $3.6 \mathrm{~nm}$ iron nanoparticles. Fe@C catalysts that are reduced and carburized render the formation of hexagonal $\varepsilon^{\prime}-\mathrm{Fe}_{2.2} \mathrm{C}$ and $\mathrm{Hägg} \chi-\mathrm{Fe}_{5} \mathrm{C}_{2}$ carbide under LTFT, respectively, with a similar degree of carburization, particle size and stability. Thus, the different activation methods provided control over the iron phase under steady-state LTFT, whereas other physiochemical properties were not altered. It is found that $\varepsilon^{\prime}-\mathrm{Fe}_{2.2} \mathrm{C}$ and $\chi-\mathrm{Fe}_{5} \mathrm{C}_{2}$ possess equal catalytic activity in the particle size range of 3.6-6.0 nm, however, between the two activation methods there is a clear difference in selectivity. The increased hydrogenation ability of the $\varepsilon^{\prime}-\mathrm{Fe}_{2.2} \mathrm{C}$ iron phase, demonstrated by a higher methane selectivity and lower $\mathrm{C}_{5+}$ selectivity, indicates that there are deviations in the surface chemistry of the two carbides. These deviations originate either from intrinsic differences of the surface sites formed on the two types of iron carbides, or are related to the differences in relative coverage of hydrogen and carbon following the activation procedure. The activity of Fe@C catalysts under LTFT at $230{ }^{\circ} \mathrm{C}$ is noteworthy, as other iron catalysts remain below Fe@C activity values up to operating temperatures of $260-270{ }^{\circ} \mathrm{C}$. The necessity of LTFT operation to maintain single-phase $\varepsilon^{\prime}-$ $\mathrm{Fe}_{2.2} \mathrm{C}$ carbide was verified with additional experiments of Fe@C under HTFT conditions, causing interconversion of $\varepsilon^{\prime}-\mathrm{Fe}_{2.2} \mathrm{C}$ into a mixture of $\chi-\mathrm{Fe}_{5} \mathrm{C}_{2}$ and $\varepsilon^{\prime}-\mathrm{Fe}_{2.2} \mathrm{C}$ under the lower carbon chemical potential conditions. A similar coexistence of iron carbide phases was obtained for directly carburized catalysts, and comparison under HTFT resulted identical activity and selectivity for both reduced and carburized Fe@C catalysts. Spent catalysts of the LTFT performance tests were examined by TEM and confirmed that the high iron dispersion was maintained, demonstrating the absence of sintering phenomena that cause formation of large inactive iron clusters and interconversion of iron carbide 
phases. The retained dispersion furthermore confirms that the difference in catalyst selectivity is only obtained by the different activation methods for both catalysts with similar particle size. Hence, it is concluded that the variation in product selectivity is likely associated to the different iron carbide phases.

\section{Acknowledgements}

TAW wishes to thank the TU Delft central library staff in their quest for locating the antique literature cited in this paper.

\section{Author affiliation}

[a] T.A. Wezendonk, X. Sun, F. Kapteijn and J. Gascon, Chemical Engineering, Catalysis Engineering Section, Delft University of Technology, Van der Maasweg 9, 2629 HZ, Delft.

[b] T.A. Wezendonk, J. Gascon, King Abdullah University of Science and Technology, KAUST Catalysis Center, Advanced Catalytic Materials, Thuwal 23955, Saudi Arabia. *jorge.gascon@kaust.edu.sa

[c] A.I. Dugulan, Fundamental Aspects of Materials and Energy, Delft University of Technology, Mekelweg 15, $2629 \mathrm{JB}$, Delft.

[d] A.J.F. van Hoof, E.J.M Hensen, Eindhoven University of Technology, Inorganic Materials Chemistry, Helix 14, STW 4.33, Groene Loper 5, 5612AE, Eindhoven

\section{Supplementary material}

Supplementary data associated with this article can be found in the online version at dx.doi/org.

\section{References}

[1] Fischer, F., Tropsch, H., Brennst.-Chem., 7 (1926) 97.

[2] Fischer, F., Tropsch, H., Brennst.-Chem., 11 (1930) 489.

[3] Fischer, F., Tropsch, H., Ges. Abh. Kenntn. Kohle, 10 (1930) 313.

[4] Pichler, H., Kruger, E., Brennstoff-Chemie, 47 (1966) 368.

[5] Malan, O.G., Louw, J.D., Ferreira, L.C., Brennst.-Chem., 42 (1961) 209-212.

[6] Barton, G.H., Gale, B., Acta Crystallogr., 17 (1964) 1460-1462.

[7] Eckstrom, H.C., Adcock, W.A., J. Am. Chem. Soc., 72 (1950) 1042-1043.

[8] Fasiska, E.J., Jeffrey, G.A., Acta Crystallogr., 19 (1965) 463-471.

[9] Hägg, G., Z. Kristallogr., 89 (1934) 92.

[10] Hofer, L.J.E., Cohn, E.M., Peebles, W.C., J. Am. Chem. Soc., 71 (1949) 189-195.

[11] Hofmann, U., Groll, E., Z. Anorg. Allg. Chem., 191 (1930) 414-428. 
[12] Senateur, J.P., Fruchart, R., Michel, A., Compt. Rend., 255 (1962) 1615.

[13] Herbstein, F.H., Snyman, J.A., Inorg. Chem., 3 (1964) 894-896.

[14] Ron, M., Mathalone, Z., Physical Review B, 4 (1971) 774-777.

[15] Mitchell, J.J., J. Chem. Phys., 21 (1953) 1153-1159.

[16] Pichler, H., Merkel, H., Brennst.-Chem., 31 (1950) 33-42.

[17] Nagakura, S., J. Phys. Soc. Jpn., 14 (1959) 186-195.

[18] Mitchell, J.J., The Journal of Chemical Physics, 21 (1953) 1153-1159.

[19] Shultz, J.F., Hall, W.K., Seligman, B., Anderson, R.B., J. Am. Chem. Soc., 77 (1955) 213-221.

[20] Bernas, H., Campbell, I.A., Fruchart, R., J. Phys. Chem. Solids, 28 (1967) 17-24.

[21] Amelse, J.A., Butt, J.B., Schwartz, L.H., J. Phys. Chem., 82 (1978) 558-563.

[22] Raupp, G.B., Delgass, W.N., J. Catal., 58 (1979) 348-360.

[23] Raupp, G.B., Delgass, W.N., J. Catal., 58 (1979) 337-347.

[24] Raupp, G.B., Delgass, W.N., J. Catal., 58 (1979) 361-369.

[25] Schäfer-Stahl, H., Angew. Chem. Int. Ed., 19 (1980) 729-731.

[26] Niemantsverdriet, J.W., Van der Kraan, A.M., Van Dijk, W.L., Van der Baan, H.S., J. Phys. Chem., 84 (1980) 3363-3370.

[27] Niemantsverdriet, J.W., van der Kraan, A.M., J. Catal., 72 (1981) 385-388.

[28] Jung, H.J., Vannice, M.A., Mulay, L.N., Stanfield, R.M., Delgass, W.N., J. Catal., 76 (1982) 208-224.

[29] Jung, H.J., Walker, P.L., Vannice, A., J. Catal., 75 (1982) 416-422.

[30] Reymond, J.P., Mériaudeau, P., Teichner, S.J., J. Catal., 75 (1982) 39-48.

[31] Blanchard, F., Reymond, J.P., Pommier, B., Teichner, S.J., J. Mol. Catal., 17 (1982) 171-181.

[32] Kuivila, C.S., Stair, P.C., Butt, J.B., J. Catal., 118 (1989) 299-311.

[33] Dictor, R.A., Bell, A.T., J. Catal., 97 (1986) 121-136.

[34] Bukur, D.B., Koranne, M., Lang, X., Rao, K.R.P.M., Huffman, G.P., Appl. Catal., A, 126 (1995) 85-113.

[35] Shroff, M.D., Kalakkad, D.S., Coulter, K.E., Kohler, S.D., Harrington, M.S., Jackson, N.B., Sault, A.G., Datye, A.K., J. Catal., 156 (1995) 185-207.

[36] O'Brien, R.J., Xu, L., Spicer, R.L., Davis, B.H., Energy \& Fuels, 10 (1996) 921-926.

[37] Herreyre, S., Gadelle, P., Moral, P., Millet, J.M.M., J. Phys. Chem. Solids, 58 (1997) 1539-1545.

[38] Bukur, D.B., Lang, X., Ding, Y., Appl. Catal., A, 186 (1999) 255-275.

[39] Li, S., O’Brien, R.J., Meitzner, G.D., Hamdeh, H., Davis, B.H., Iglesia, E., Appl. Catal., A, 219 (2001) 215222.

[40] Li, S., Ding, W., Meitzner, G.D., Iglesia, E., J. Phys. Chem. B, 106 (2002) 85-91.

[41] Hao, Q., Bai, L., Xiang, H., Li, Y., J. Nat. Gas Chem., 18 (2009) 429-435.

[42] de Smit, E., Cinquini, F., Beale, A.M., Safonova, O.V., van Beek, W., Sautet, P., Weckhuysen, B.M., J. Am. Chem. Soc., 132 (2010) 14928-14941.

[43] Santos, V.P., Wezendonk, T.A., Jaén, J.J.D., Dugulan, A.I., Nasalevich, M.A., Islam, H.-U., Chojecki, A., Sartipi, S., Sun, X., Hakeem, A.A., Koeken, A.C.J., Ruitenbeek, M., Davidian, T., Meima, G.R., Sankar, G., Kapteijn, F., Makkee, M., Gascon, J., Nat Commun, 6 (2015) 1-8.

[44] Wezendonk, T., Warringa, Q.S.E., Da Costa Oliveira Santos Silva, V., Chojecki, A., Ruitenbeek, M., Meima, G., Makkee, M., Kapteijn, F., Gascon, J., Faraday Discuss., (2016).

[45] Wezendonk, T.A., Santos, V.P., Nasalevich, M.A., Warringa, Q.S.E., Dugulan, A.I., Chojecki, A., Koeken, A.C.J., Ruitenbeek, M., Meima, G., Islam, H.-U., Sankar, G., Makkee, M., Kapteijn, F., Gascon, J., ACS Catal., 6 (2016) 3236-3247.

[46] Sartipi, S., Jansma, H., Bosma, D., Boshuizen, B., Makkee, M., Gascon, J., Kapteijn, F., Rev. Sci. Instrum., 84 (2013) 124101.

[47] Klencsár, Z., Nucl. Instrum. Methods Phys. Res., Sect. B, 129 (1997) 527-533.

[48] Alves Jr, N., Caetano, E.P., Rodríguez, V.P., Baggio-Saitovitch, E., Determination of Debye Temperature from Mössbauer Data, in, Centro Brasileiro de Pesquisas Fisicas (CBPF), 1995.

[49] De Grave, E., Verbeeck, A.E., Chambaere, D.G., Phys. Lett. A, 107 (1985) 181-184.

[50] McCammon, C.A., Price, D.C., Phys. Chem. Miner., 11 250-254.

[51] Hazen, R.M., Jeanloz, R., Rev. Geophys., 22 (1984) 37-46.

[52] Bauer, E., Pianelli, A., Mater. Res. Bull., 15 (1980) 177-188.

[53] Le Caer, G., Dubois, J.M., Senateur, J.P., J. Solid State Chem., 19 (1976) 19-28. 
[54] Barinov, V.A., Tsurin, V.A., Kazantsev, V.A., Surikov, V.T., Phys. Met. Metallography, 115 (2014) 53-68.

[55] Amelse, J.A., Schwartz, L.H., Butt, J.B., J. Catal., 72 (1981) 95-110.

[56] Van Sciver, S.W., Low-Temperature Materials Properties, in: S.W. Van Sciver (Ed.) Helium Cryogenics, Springer New York, New York, NY, 2012, pp. 17-58.

[57] Canepa, P., Tan, K., Du, Y., Lu, H., Chabal, Y.J., Thonhauser, T., J. Mater. Chem. A, 3 (2015) 986-995.

[58] Huang, B.L., McGaughey, A.J.H., Kaviany, M., Int. J. Heat Mass Transf., 50 (2007) 393-404.

[59] Lorusso, G., Palacios, M.A., Nichol, G.S., Brechin, E.K., Roubeau, O., Evangelisti, M., Chem. Commun., 48 (2012) 7592-7594.

[60] Lorusso, G., Sharples, J.W., Palacios, E., Roubeau, O., Brechin, E.K., Sessoli, R., Rossin, A., Tuna, F., McInnes, E.J.L., Collison, D., Evangelisti, M., Adv. Mater., 25 (2013) 4653-4656.

[61] Fe304: heat capacity, Debye temperature: Datasheet from Landolt-Börnstein - Group III Condensed Matter · Volume 41D: "Non-Tetrahedrally Bonded Binary Compounds II" SpringerMaterials, in: P. Villars (Ed.), Springer-Verlag Berlin Heidelberg.

[62] Fe rt $m$ Debye/Einstein temperature: Datasheet from "Pauling File Multinaries Edition - 2012" SpringerMaterials, in: P. Villars (Ed.), Springer-Verlag Berlin Heidelberg; Material Phases Data System (MPDS), Switzerland; and National Institute for Materials Science (NIMS), Japan.

[63] Fe3O4 It rhom Debye/Einstein temperature: Datasheet from "Pauling File Multinaries Edition - 2012" SpringerMaterials, in: P. Villars (Ed.), Springer-Verlag Berlin Heidelberg; Material Phases Data System (MPDS), Switzerland; and National Institute for Materials Science (NIMS), Japan.

[64] $\mathrm{FeO}(\mathrm{Fe}(1-\mathrm{x}) \mathrm{O})$ : elastic moduli, Debye temperature: Datasheet from Landolt-Börnstein - Group III Condensed Matter · Volume 41D: "Non-Tetrahedrally Bonded Binary Compounds II" SpringerMaterials, in: O. Madelung, U. Rössler, M. Schulz (Eds.), Springer-Verlag Berlin Heidelberg.

[65] Guillermet, A.F., Grimvall, G., J. Phys. Chem. Solids, 53 (1992) 105-125.

[66] Xu, K., Sun, B., Lin, J., Wen, W., Pei, Y., Yan, S., Qiao, M., Zhang, X., Zong, B., Nat Commun, 5 (2014).

[67] van Steen, E., Prinsloo, F.F., Catal. Today, 71 (2002) 327-334.

[68] Li, S., Krishnamoorthy, S., Li, A., Meitzner, G.D., Iglesia, E., J. Catal., 206 (2002) 202-217.

[69] Withers, H.P., Eliezer, K.F., Mitchell, J.W., Ind. Eng. Chem. Res., 29 (1990) 1807-1814.

[70] Quu, B., Yang, C., Guo, W., Xu, Y., Liang, Z., Ma, D., Zou, R., J. Mater. Chem. A, 5 (2017) 8081-8086.

[71] Reed, T.B., Free Energy of Formation of Binary Compounds: An Atlas of Charts for High-Temperature Chemical Calculations, MIT Press, Cambridge, MA, 1971.

[72] Retief, J.J., Powder Diffr., 14 (2013) 130-132.

[73] Steynberg, P.J., Berg, J.A.v.d., Rensburg, W.J.v., J. Phys.: Condens. Matter, 20 (2008) 064238.

[74] Petersen, M.A., van den Berg, J.-A., van Rensburg, W.J., J. Phys. Chem. C, 114 (2010) 7863-7879.

[75] Sorescu, D.C., J. Phys. Chem. C, 113 (2009) 9256-9274.

[76] Anderson, R.B., Catalysis, in: P.H. Emmett (Ed.), Van Nostrand-Reinhold, New York, 1956, pp. 29.

[77] Storch, H.H., Golumbic, N., Anderson, R.B., The Fischer-Tropsch and Related Syntheses, John Wiley \& Sons, Inc., New York, 1951.

[78] Hansen, T.W., DeLaRiva, A.T., Challa, S.R., Datye, A.K., Acc. Chem. Res., 46 (2013) 1720-1730.

[79] Torres Galvis, H.M., Bitter, J.H., Davidian, T., Ruitenbeek, M., Dugulan, A.I., de Jong, K.P., J. Am. Chem. Soc., 134 (2012) 16207-16215.

[80] Xie, J., Yang, J., Dugulan, A.I., Holmen, A., Chen, D., de Jong, K.P., Louwerse, M.J., ACS Catal., 6 (2016) 3147-3157. 